\title{
The Relationship Between Driving Aberrant Behavior and Self-Reported Accidents Involvement Amongst Professional Bus Drivers in the Public Transportation Company
}

\author{
Sakineh Varmazyar ${ }^{1}$, Seyed Bagher Mortazavi ${ }^{1, *}$, Ebrahim Hajizadeh ${ }^{2}$, Shirazeh Arghami ${ }^{3}$ \\ 1 Department of Occupational Health Engineering, Faculty of Medical Sciences, Tarbiat Modares University, Theran, IR Iran \\ 2 Department Of Bio-statistical, Faculty of Medical Sciences, Tarbiat Modares University, Theran, IR Iran \\ ${ }^{3}$ Department of Occupational Health Engineering, Zanjan University of Medical sciences, Zanjan, IR Iran \\ ${ }^{*}$ Corresponding author: Seyed Bagher Mortazavi, Department of Occupational Health Engineering, Faculty of Medical Sciences, Tarbiat Modares University, Theran, IR Iran. Tel./Fax: \\ +98-2182883825, E-mail: Mortazav@modares.ac.ir.
}

Received: April 13, 2013; Revised: Jun 10, 2013; Accepted: Jun 11, 2013

\begin{abstract}
Background:The mostaccidents can be directlyattributed to human factors. Hence, more traffic crashes resultfromdrivermalfunctioning which from among them, the driver behavior is a proximal factor in the road traffic injuries causation chain.

Objectives: This study aims to investigate relationship between aberrant driving behaviors questionnaire (DBQ factors) and self-report crashes involvement amongst professional bus drivers of public transportation system.

Materials and Methods: This analytical descriptive study was performed on 161 urban bus drivers in Tehran. Proportional sampling method was used to select drivers from nine systems or areas. Data were collected through questionnaire including driver's behavior and their demographic information. Validity and reliability of the driver's behavior questionnaire for bus drivers had been confirmed in a previous study. Data collection was analyzed by Pearson correlation and regression logistic of in SPSS 16 of software.

Results: Drivers reported accident involvement during the past three years with mean and standard deviation $2.4 \pm 3.2$, so that $31.1 \%$ had been involved in three or more accidents. There was a negative significant correlation between age and risky violation $(\mathrm{P}=0.01)$. Furthermore, accidents involvement in the last three years was positively correlated with working hours per week $(\mathrm{P}=0.003)$ and traffic offences $(\mathrm{P}=0.005)$. Mistake as a driving aberrant behavior had a direct significant relationship with annual mileage $(\mathrm{P}=0.020)$ and accidents involvement in last three years $(\mathrm{P}=0.025)$.

Conclusions: Bus driver's crashes can be reduced by less driving time and mistakes which is dependent on mileage they drive.
\end{abstract}

Keywords: Behavior; Accident; Professional; Driver; Bus; Public; Transport

\section{Background}

Road traffic accidents are considered to be the second highest cause of mortality in Iran (highest cause is coronary heart disease) (1). Also world health organization (WHO) statistics show that Iran has one of the highest rates of morbidities and mortalities due to traffic accidents in the world, which occurs for professional and nonprofessional drivers and motorcyclists, pedestrians, etc (2). The study results identified that human factors are as probable causes in $93 \%$ of the investigated crashes while environmental factors and vehicular factors are the probable causes only in $34 \%$ and $13 \%$, respectively (3). So, most accidents can be directly attributed to human factors (4). Hence, more traffic crashes result from driver malfunctioning rather than from a technical failure of the vehicle (5). Reason et al. (1990) divided human risk behavior to errors and violations, and developed a survey instrument, driver behavior questionnaire (DBQ), to measure these concepts in driver behavior (5). It is a method for studying self-reported aberrant driving behaviors and their relationship with different variables and crash involvement (6). The main distinction between errors and violations is based on the assumption that they have different psychological origins and demand different modes of remediation (Reason et al., 1990). Errors are the result of cognitive processing problems, whereas violations include a motivational component and contextual demands (4). Errors as the failure of planned actions to achieve their intended consequences $(4,5)$ (e.g., brake too quickly on a slippery road). Errors subcategory included slip, lapse and mistake (5, 7-9). Slips and lapses included attention and memory failures $(5,6)$ (e.g., attempt to drive away from traffic lights in third gear) (10). Mistake the plan itself may be inappropriate due to deficiencies in knowledge and judgment (8). Violations defined as "deliberate deviations from those practices believed necessary to maintain the safe operation 
of a potentially hazardous system" $(4,5,11)$ also violation as conscious deviations from rules or safe practices (e.g., driving above the speed limit) (10). Unlike errors, violations were seen as deliberate behaviors, although both errors and violations are potentially dangerous and could lead to a crash. "Risky violation (RV)" in which aberrant behaviors is always deliberate, highly risky, and non-emotional. Drivers choose to take risks for convenience or profit in these cases (10). "Highway violations" consists of behaviors like speeding and running red lights. Furthermore, Highway violations focus on "gaining advantage" (e.g., speeding, overtaking). There is extensive evidence that it is only the violations score which is significantly correlated with and predictive of crash involvement. However there are different patterns of correlations with crash involvement (9). Whereas the few researchers have studied the crash risk of professional drivers in public transportation bus system due to aberrant behavior and given this previous research has vouched that there have been differences in the relationship between DBQ scores and crash involvement (9).

\section{Objectives}

The aims of the present study were to survey relationship between demographic variables, driving exposure and the DBQ factor (aberrant driving behaviors) and crash involvement for urban bus drivers.

\section{Materials and Methods}

\subsection{Participants and Procedure}

The study subjects were bus drivers working for public transportation company in Tehran. This company is run under Tehran municipality supervision to transport Tehran citizens and surrounding area inhabitants efficiently to manage city traffic volume. Drivers work in nine bus systems or areas located either in the city of Tehran or milieu re- gions. There are five systems of bus rapid transit, three areas with normal lines and a Trolleybus route. In this study, 161 professional bus drivers were randomly selected from the nine bus systems or areas through a random proportional sampling method with the help of bus lines supervisors. An identification code was added to the questionnaires (demographic, driving information and driver behavior questionnaire) in order to match the responses. The researcher held an interview session with drivers in groups of $5-20$ people. The researcher explained about the aims of the study and the questionnaires to be filled out. Drivers were asked to complete the questionnaire anonymously and return it in that session.

\subsection{Measures}

\subsubsection{Drivers Behavior Questionnaire}

In this study, we used the 15 items version of Drivers Behavior Questionnaire (DBQ). Validity and reliability of the questionnaire was approved in a previous study by the researchers (12). Primary version of questionnaire included 50 items (12) from which unnecessary and irrelevant items for bus drivers (24 items) were eliminated after testing face and content validity for this population. An exploratory factor analysis with varimax rotation was used for loading of remaining 26 items to select the most informative factors of the DBQ. Factor analysis suggested an acceptable four factors solution (Risky Violation, slip and lapse, Highway Violation and mistake) with $45.15 \%$ total variance (Table 1). Due to small amount of variation explained by other factors, those factors did not interpreted (13). The Alpha coefficient and Spearman's rho correlation coefficient in test-retest were calculated 0.85 and 0.74 respectively. Therefore, the 15 item version of DBQ including four factors was used in the present study. Drivers responded to equations on the basis of five-point likert scale. $(0=$ never to $4=$ nearly all the time).

Table 1. Number of Items and Variance Each the Factors Questionnaire

\begin{tabular}{lll}
\hline Aberrant Behavior & Number of Items & Amount of Explained Variance, \% \\
\hline Risky violation & 5 & 22.9 \\
Slip and lapses & 4 & 11 \\
Highway violation & 3 & 6.36 \\
Mistake & 3 & 4.89 \\
\hline
\end{tabular}

\subsubsection{Demographic and Driving Exposure Measures}

Participants answered questions about age, education, marital status, total driving experience (year), driving experience in the bus company as a bus drivers (year), weekly driving time (hour), annual mileage (kilometer/hour), number of crashes and traffic offences (financial penalties driver by police due to violation of traffic regulations) in the last three years.

\subsection{Statistical Analyses}

The relationship between main variables (demographic, driving information and driver's behavior) as independent variables with accident involvement in the last three years as dependent variable investigated via Pearson correlation coefficient and odds ratio in binominal regression logistic. Data collected from study were analyzed using SPSS 16 the software. 


\section{Results}

\subsection{Participants and Driving Exposure}

The sample consisted of 161 drivers from nine systems and areas in different sectors of the city in urban public transportation bus company: express systems of routes, one $(5 \%, \mathrm{n}=8)$; two $(21.7 \%, \mathrm{n}=35)$; three $(7.5 \%, \mathrm{n}=12)$; four $(16.1 \%, \mathrm{n}=26)$; ten $(6.2 \%, \mathrm{n}=10)$; areas with normal lines, six $(16.8 \%, \mathrm{n}=27)$; $\operatorname{seven}(8.1 \%, \mathrm{n}=13)$, nine $(15.5 \%, \mathrm{n}=25)$ and Trolleybus system $(3.1 \%, n=5)$. Results indicated that mean and standard deviation of age of the participants was $39.9 \pm 4.84$ years old with range of $30-50$ years. All of the participants were male, of which $99.4 \%$ were married. $46 \%(\mathrm{n}=74)$ of drivers had the education of secondary school, 24.2\% ( $n=39)$ high school, 29.2\% $(n=47)$ diploma and $6 \%(n=1)$ had education of association degree. Mean and standard deviation driving-related information provided in Table 2.

\subsection{The Factors Scores}

Mean and standard deviation of factor scores or drivers' aberrant behaviors is presented in Table 3 .

\subsection{Self-reported Accidents Involvement}

From all 161 bus drivers, $31.1 \%$ had been involved in three or more accidents in the last three years (Table 4).

\subsection{Correlation Between Main Variables}

The results related to correlation between demographic variables, driving information, driver's behavior and selfreport crash in the last three years is provided in Table 5.

\subsection{Regression Analysis}

The results of binominal logistic regression analysis with self-report accident involvement (occurrence or non-occurrence) in the last three years as dependent variable and demographic, driving information and drivers' behavior as independent variables are presented in Table 6.

(B) It logistic coefficient for each predictor variable. The logistic coefficient (B) is the expected amount of change in the logit for each one unit change in the predictor. The logit is what is being predicted; it is the odds of membership in the category of the outcome variable with the numerically higher value (here a one, rather than zero). The closer a logistic coefficient to zero is, the less influence it has in predicting the logit. The Wald test (and associated p-value) is used to evaluate whether or not the logistic coefficient is different than zero. The $\operatorname{Exp}(\mathrm{B})$ is the odds ratio associated with each predictor. We expect predictors which increase the logit to display $\operatorname{Exp}(\mathrm{B})$ greater than one, those predictors which do not have an effect on the logit will display an $\operatorname{Exp}(\mathrm{B})$ of one and predictors which decease the logit will have $\operatorname{Exp}(\mathrm{B})$ values less than one.

Table 2. Driving Exposure Characteristics and Crash Involvement of Study Sample ( $n=161)$

\begin{tabular}{ll}
\hline Variables (scale) & Mean \pm SD \\
\hline Total driving experience, $\mathbf{y}$ & $17.52 \pm 5.12$ \\
\hline Driving experience in bus company, $\mathbf{y}$ & $11.59 \pm 3.34$ \\
Maximum speed, $\mathbf{k m} / \mathbf{h}$ & $52.98 \pm 12.99$ \\
\hline Driving time in week, $\mathbf{h}$ & $58.46 \pm 7.12$ \\
\hline Annual mileage, $\mathbf{k m}$ & $34786.1 \pm 11960.7$ \\
\hline Accidents involved in previous 3 years $(\mathbf{N o})$ & $2.4 \pm 3.2$ \\
\hline
\end{tabular}

Table 3. Mean and Standard Deviation of Driver Aberrant Behavior

\begin{tabular}{ll}
\hline Aberrant Behavior, Items & Mean $\pm \mathbf{S D}$ \\
\hline Risky violation, $\mathbf{5}$ & $2.8 \pm 2.31$ \\
Slip and lapses, $\mathbf{4}$ & $2.59 \pm 1.98$ \\
Highway violation, $\mathbf{3}$ & $1.73 \pm 1.69$ \\
Mistake, 3 & $2.61 \pm 1.74$ \\
\hline
\end{tabular}

Table 4. Number of Drivers Involved in Accident in Previous 3 Years

\begin{tabular}{lll}
\hline Accidents involving, No & Drivers, No & Percentage \\
\hline $\mathbf{0}$ & 43 & $26.7 \%$ \\
$\mathbf{1}$ & 29 & $18 \%$ \\
$\mathbf{2}$ & 39 & $24.2 \%$ \\
$\geq 3$ & 50 & $31.1 \%$ \\
\hline
\end{tabular}




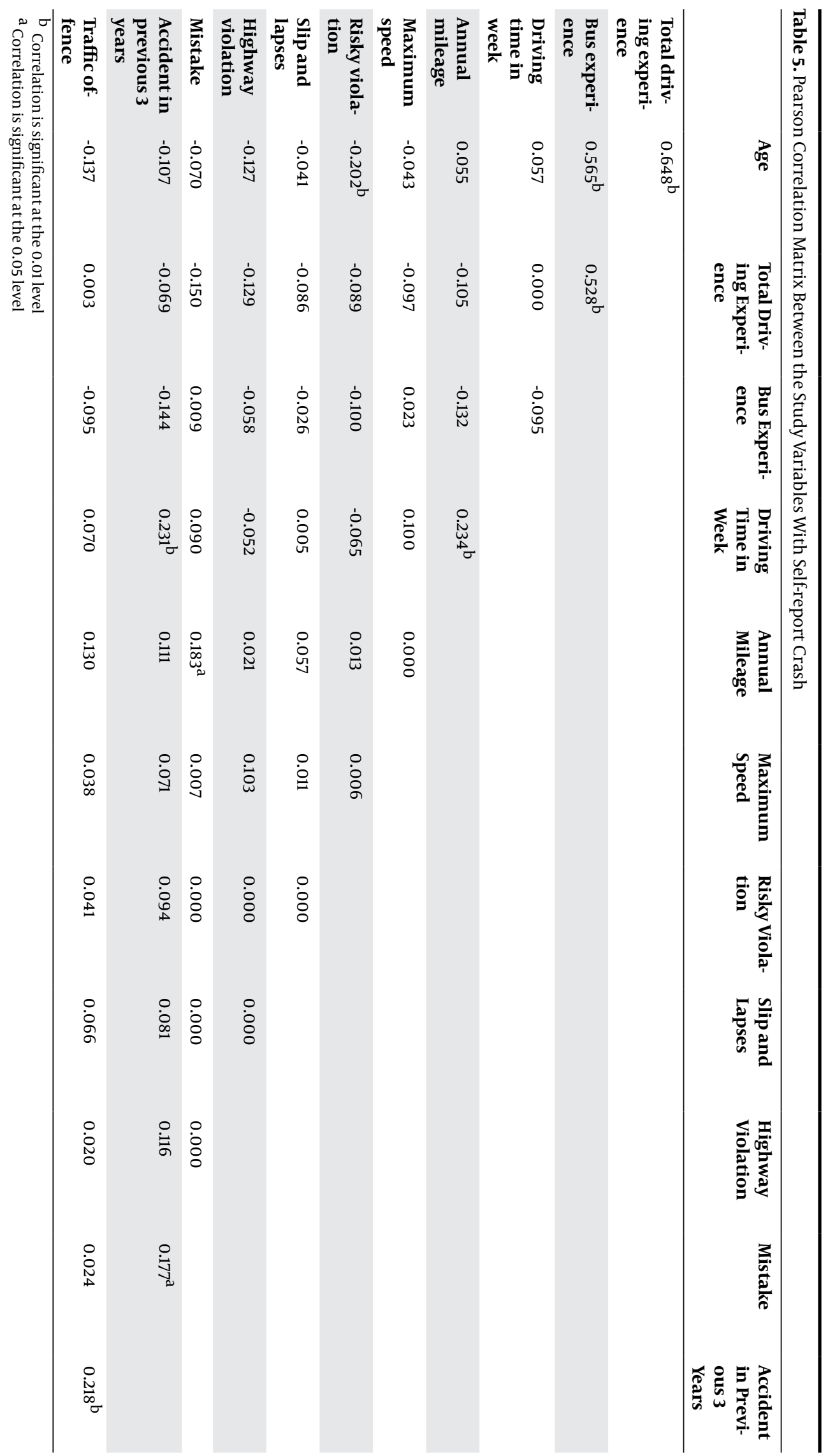


Varmazyar S et al.

\begin{tabular}{lllllll}
\hline Table 6. Results of Regression Analysis & & & & & \\
\hline & Logistic Coefficient & Wald & Sig & Odds ratio & 95\% Confidence interval for Odds ratio \\
\hline Predictor variables & & & & & Lower & Upper \\
\hline age & 0.047 & 0.726 & 0.395 & 1.048 & 0.941 & 1.167 \\
Total driving experience & -0.020 & 0.156 & 0.693 & 0.980 & 0.887 & 1.083 \\
\hline Bus experience & -0.023 & 0.107 & 0.743 & 0.977 & 0.852 & 1.121 \\
\hline Driving time in week & -0.022 & 0.610 & 0.430 & 0.978 & 0.926 & 1.034 \\
Annual mileage & 0.000 & 0.303 & 0.581 & 1.000 & 1.000 & 1.000 \\
\hline Maximum speed & -0.003 & 0.052 & 0.820 & 0.997 & 0.968 & 1.026 \\
Risky violation & -0.015 & 0.026 & 0.871 & 0.985 & 0.821 & 1.182 \\
Slip and lapses & -0.137 & 1.235 & 0.266 & 0.872 & 0.685 & 1.110 \\
Highway violation & -0.051 & 0.152 & 0.697 & 0.950 & 0.732 & 1.230 \\
Mistake & 0.032 & 0.052 & 0.820 & 1.033 & 0.782 & 1.363 \\
Traffic offence & -0.409 & 1.426 & 0.232 & 0.664 & 0.339 & 1.300 \\
\hline
\end{tabular}

\section{Discussion}

Self-reports can be a very useful and efficient means for studying aberrant driving behavior. At their best, anonymous surveys can provide reliable in-depth information about behavior, as well as about the motives and attitudes leading to risky driving. One of the widely used instruments for measuring self-reported driving is Driver Behavior Questionnaire (DBQ) (5). In this study bus drivers' behavior in urban public transit company was investigated using DBQ, and then the relationship between drivers' behavior and self-report crash in the last three years was evaluated. The results from Table 2 show that the drivers , in average, were involved in two crashes (Mean $=2.4$ ) over the last three years, however some of them may have been involved in less accidents or even have had no incident and some have reported more than two crashes. According to the results of Table 3 it is denoted that 31\% of the bus drivers or in other words a third of the drivers, were involved in the three accidents or more in the last three years. Also, the results of this table indicate that nearly $73 \%$ of drivers had at least one accident in the past three years. Therefore is necessary attendance to effective agents on accidents.According to the expectations (Table5), there is a correlation between driver's age with total driving experience and bus experience, so that older drivers generally have more experience. Also both experiences (Total and bus) together have significant and direct association. The results in Table 5 showed that risky violations have significant and negative correlation with age $(r=-0.202$ in error level of less than 0.01 and confidence interval 99\%) namely young drivers reported greater risky violations.The result is in line with the study of Sullman amongst New Zealand truck drivers that both violation and aggressive violation were in a significant negative correlation with age (9). Given that in present study risky violations were related to cases such as not keeping the necessary distance from the car in front, mount and discount passengers out of the station, overtaking the slow moving vehicle, it is more likely that risky behaviors emerges among young drivers. Slip and lapse and highway violation are not significantly correlated with any of the main variables.In the present study, driving duration in weekdays had significant and positive correlation with annual mileage $(r=0.234)$ that naturally means more time and more traveled kilometers which is in line with others studies $(9,14)$. As well as all mentioned, driving time in week had meaningful and direct relation with self-reported accident in last three years ( $r$ $=0.231$ ) . This means that more hours of driving per week cause fatigue increase, decrease of attention and judgment of driver while driving and thus will result in accident.Correlations between mistake while driving with annual mileage $(r=0.183)$ and self-reported accident $(r=$ 0.177 ) indicated that there is significant and positive association in error level of less than 0.05 and confidence interval of $95 \%$ namely with reduce kilometer traveled, mistakes decrease and so does involvement in accident. There is a significant and direct relevance between traffic offences of driving and accident involvement ( $\mathrm{r}=$ 0.218).This means that drivers with more traffic offences may be more prone for involvement in crashes that is consistent with Davey study (14). Results of logistic regression analysis (Table 6) showed that none of the demographic variables, driving information and driver behaviors had ability to predict crash in the last three years. While in the study of Rowland three variables of: Km per year, errors and work pressure were predictive of crash risk in the last years in Australian (15). Also in the Sullman study, age (young drivers) and aggression violation variables based on logistic regression have odds ratio of 6.6 and 1.5 times for prediction of crashes involvement (9) and in the research of Bener, errors predict accident involvement with odds ratio of 2.8 (7). 
In the Tronsmoenstudy with the aim of is to examining associations between crash involvement on one hand and young drivers' safety attitudes (aged 18 - 20 years), self-assessment of driving ability and self-reported driver behavior on the other hand. The results show that Young novice drivers' crash involvement seems stronger associated with driving skills (manifested as self assessment of driving ability) than safety attitudes and self-reported driver behaviors (16).Given that driving style (motives, attitudes and personality traits) and driving skills (information processing and motor skills) can interact together to influence crash risk, use of safety margins, the probability of errors and recovery from errors (4), are necessary to reduce errors and violations in order to decrease socio-economical problems and community burdens (7). Errors are the result of cognitive processing problems, whereas violations include motivational component and contextual demands (4). Thus errors may be reduced via participation in skillbased training courses in the deployment of attention resources (11), while violations can be minimized by attempting to change attitudes, beliefs and social norms (8). Given that $73 \%$ of the drivers were involved at least once in crashes during past three years and driving time, mistake and number of traffic offences are effective agents in occurrence of crashes, it is essential to reduce driving time during the day. Also, in order to reduce mistakes and traffic offences while driving it is essential to accurate statistics of accidents and traffic offences created due to mistake provided to drivers via bus company, likewise training courses are held in field of increase attention and precision in observations and judgments of drivers' and prevents violation in order to increase traffic offences.

\section{Acknowledgements}

The authors express their gratitude to senior managers of Bus Company and middle managers and HSE experts of transport Bus Company.

\section{Authors' Contribution}

All authors in this study have made extensive contribution.

\section{Financial Disclosure}

There is no financial disclosure.

\section{Funding/Support}

This research was funded by Tarbiat Modares University.

\section{References}

1. Montazeri A. Road-traffic-related mortality in Iran: a descriptive study. Public Health. 2004;118(2):110-3.

2. Attarchi MS, Dehghan F, Seyedmehdi SM, Mohammadi S. Traffic accidents and related injuries in Iranian professional drivers. Journal of Public Health. 2012;20(5):499-503.

3. Chandraratna S, Stamatiadis N, Stromberg A. Crash involvement of drivers with multiple crashes. Accid Anal Prev. 2006;38(3):532-41.

4. Ozkan T, Lajunen T, Summala H. Driver Behaviour Questionnaire: a follow-up study. Accid Anal Prev. 2006;38(2):386-95.

5. Lajunen T, Parker D, Summala H. The Manchester Driver Behaviour Questionnaire: a cross-cultural study. Accid Anal Prev. 2004;36(2):231-8.

6. Shi J, Bai Y, Ying X, Atchley P. Aberrant driving behaviors: a study of drivers in Beijing. Accid Anal Prev. 2010;42(4):1031-40.

7. Bener A, Ozkan T, Lajunen T. The Driver Behaviour Questionnaire in Arab Gulf countries: Qatar and United Arab Emirates. Accid Anal Prev. 2008;40(4):1411-7.

8. Kontogiannis T, Kossiavelou Z, Marmaras N. Self-reports of aberrant behaviour on the roads: errors and violations in a sample of Greek drivers. Accid Anal Prev. 2002;34(3):381-99.

9. Sullman MJ, Meadows ML, Pajo KB. Aberrant driving behaviours amongst New Zealand truck drivers. Transportation Research Part F: Traffic Psychology and Behaviour. 2002;5(3):217-39.

10. Lucidi F, Giannini AM, Sgalla R, Mallia L, Devoto A, Reichmann S. Young novice driver subtypes: relationship to driving violations, errors and lapses. Accid Anal Prev. 2010;42(6):1689-96.

11. Lawton R, Parker D, Manstead AS, Stradling SG. The role of affect in predicting social behaviors: the case of road traffic violations. Journal of Applied Social Psychology. 1997;27(14):1258-76.

12. ORIZI HR, HAGHAYEGH SA. Psychometric properties of the manchester driving behavior questionnaire. Payesh. 2010.

13. Russell DW. In search of underlying dimensions: The use (and abuse) of factor analysis in Personality and Social Psychology Bulletin. Personality and social psychology bulletin. 2002;28(12):1629-46.

14. Davey J, Wishart D, Freeman J, Watson B. An application of the driver behaviour questionnaire in an Australian organisational fleet setting. Transportation Research Part F: Traffic Psychology and Behaviour. 2007;10(1):11-21.

15. Rowland BD, Davey JD, Freeman JE, Wishart DE. Work-related road safety risk assessment: utilisation of self-report surveys to predict organisational risk. 2008.

16. Tronsmoen T. Associations between driver training, determinants of risky driving behaviour and crash involvement. Safety Science. 2010;48(1):35-45. 